\title{
Conservative management of a complex ovarian cyst in a case of Glanzmann's thrombasthenia
}

\author{
Meena N. Satia ${ }^{1}$, Madhavi Jandhyala ${ }^{1}$, Vibha More ${ }^{1}$, Chandrakala Shanmukhaiah ${ }^{2}$ \\ ${ }^{1}$ Department of Obstetrics and Gynaecology, Seth G. S Medical College and KEM Hospital, Mumbai, Maharashtra, \\ India \\ ${ }^{2}$ Department of Clinical Haematology, Seth G. S Medical College and KEM Hospital, Mumbai, Maharashtra, India
}

Received: 08 April 2016

Accepted: 07 May 2016

\author{
*Correspondence: \\ Dr. Madhavi Jandhyala, \\ E-mail: jmadhavi136@gmail.com
}

Copyright: $\odot$ the author(s), publisher and licensee Medip Academy. This is an open-access article distributed under the terms of the Creative Commons Attribution Non-Commercial License, which permits unrestricted non-commercial use, distribution, and reproduction in any medium, provided the original work is properly cited.

\begin{abstract}
Complex ovarian cyst has many causes one of them being haemorrhagic cyst. Most of the haemorrhagic ovarian cyst present as an emergency, detailed clinical history is important before deciding the management. Reporting an interesting case of conservative management in a young patient of reproductive age group with variant Glanzmann's Thrombasthenia which led to a very large ovarian haemorrhagic cyst and presented as a case of torsion of the ovarian cyst. This case highlights the importance of thorough history taking and evaluation prior to embarking on surgical interference in such cases of coagulation disorders. Glanzmann's thrombasthenia (GT) is a genetic disorder which is characterized by a defect in platelet aggregation resulting in bleeding due to absence or dysfunction of the platelet glycoprotein IIb/IIIa complex. It is a rare genetic disorder that follows autosomal recessive type of inheritance.
\end{abstract}

Keywords: Glanzmann's thrombasthenia, Complex ovarian cyst, Conservative management

\section{INTRODUCTION}

Glanzmann's thrombasthenia was first documented by Dr. Eduard Glanzmann, a Swiss paediatrician in 1918, who described it as a platelet function disorder with defective clot retraction. It is a rare genetic disorder that follows autosomal recessive type of inheritance. ${ }^{1,2} \mathrm{GT}$ is a platelet disorder with an incidence of 1 in 1 million, with a deficient or dysfunctional platelet glycoprotein complex (GP IIb/IIIa) causing prolonged bleeding time and poor platelet aggregation that results in bleeding manifestations. ${ }^{3}$ Patients commonly present with purpura, petechial haemorrhages, gingival bleeding, epistaxis and menorrhagia. Less common manifestations of the disease are haematuria, hemarthrosis, gastro intestinal bleeding and haemorrhagic ovarian cysts. Menorrhagia is seen in most female patients from the time of menarche and is a serious concern as they require blood and blood products transfusion.

\section{CASE REPORT}

A 20 year old, nulligravida, married since one year presented to the Gynaecology Outpatient department with complaints of acute pain in abdomen and nausea since 2 days. On General Examination, patient was thin built, general condition fair, vital parameters stable, systemic examination was within normal limits. Abdomen examination revealed a midline mass corresponding to 22 weeks size arising from the pelvis, firm in consistency with restricted mobility. Vaginal examination findings were corresponding with abdominal finding and uterus was not felt separate from the mass. A clinical impression of torsion ovary was made. Urgent Ultrasonography of abdomen and pelvis was done that showed a large heterogeneous mass measuring $14 \times 10 \times 11 \mathrm{~cm}$ in the midline with haemorrhagic changes and absent vascularity. Right ovary could not be seen separate from the lesion and a provisional diagnosis of right ovarian torsion was made. A decision of emergency exploratory laparotomy was made in view of torsion of the ovarian 
cyst and then on further enquiry, patient's father revealed that patient had menorrhagia since puberty, episodes of epistaxis, gum bleeding and easy bruisability since childhood; also her brother had similar history and was a known case of some bleeding disorder (Glanzmann's Thrombasthenia). Hence, emergency surgery was deferred and elective surgery was planned after consultation with the haematologist. Her coagulation profile was sent. Complete blood count done was suggestive of a normal platelet count of $4 \mathrm{lacs} / \mathrm{mm} 3$, haemoglobin of $8 \mathrm{gm} \%$ with normal coagulation profile (INR, aPTT and serum Fibrinogen). Serum tumour markers were normal with CA 125 being raised-66.5 IU/L.CT scan on the same day was suggestive of a large multicystic lesion measuring $10.8 \times 14.3 \times 16.9 \mathrm{~cm}$ in the right adnexa with extension to left adnexa and lower abdomen, suggestive of a right adnexal complex cyst with subacute haemorrhage in it, and no evidence of torsion. Left ovary was normal and right ovary was not seen separate from the mass. Haematology reference was taken and in view of the positive family history of coagulation disorders, platelet function studies were advised. Platelet aggregation with ristocetin was normal and was decreased with epinephrine, collagen and Adenosine Di Phosphate (ADP). Platelet Glycoprotein receptors by flow cytometry showed Glycoprotein IIb/IIIa levels to $92.22 \%$ with normal clot retraction time. A diagnosis of platelet function disorder, variant Glanzmann's thrombasthenia was made. As per the haematologist's advice, patient was a very high risk candidate for surgery and hence, decision of surgery was deferred and conservative management was planned. Blood and blood products were kept ready. Six units of platelet transfusion and two doses of Injection Factor VII $2 \mathrm{mg}$ were administered intravenously after test dose. Intravenous tranexamic acid $500 \mathrm{mg}$ thrice daily was given for three days and later was shifted to oral. Patient was started on oral contraceptive pills (OCP). She was stable during her stay in hospital and improved symptomatically and within one week's time the size of the mass decreased from 22 weeks to 16 weeks size. Over a period of 15 days the mass decreased in size and was just palpable per abdomen and hence patient was discharged. On her follow up visit after one month, patient had normal menstrual cycles. Ultrasonography done revealed $5 \times 6 \mathrm{~cm}$ lesion in the right adnexa. Treatment with OCP was continued. Patient presented to Gynaecology OPD after 2 months with menorrhagia and OCP was given for 3 cycles.

\section{DISCUSSION}

Glanzmann's thrombasthenia is an autosomal recessive inherited disorder seen commonly in populations with consanguineous marriages. Heterozygotes are asymptomatic with normal platelet function tests. ${ }^{4}$ In normal coagulation pathways, the glycoprotein complex IIb/IIIa binds to fibrinogen when activated and bridges the platelets in the presence of calcium to form platelet aggregates that are responsible for the clotting mechanism. In patients with GT, this complex is deficient and hence, the pathology. In spite of normal platelet counts, patient exhibits bleeding manifestations. The disease is classified into three groups: type I have less than $5 \%$ of the normal GP IIb/IIIa complex with absent clot retraction; type II have 5-20\% of the normal complex with impaired clot retraction; type III are variants who have normal receptor levels but defective receptor function as was seen in our patient. ${ }^{5}$ Our patient was Type III or a variant of Glanzmann's thrombasthenia. The severity of bleeding is independent of the type of the disease and carriers or heterozygotes have normal hemostatic function.

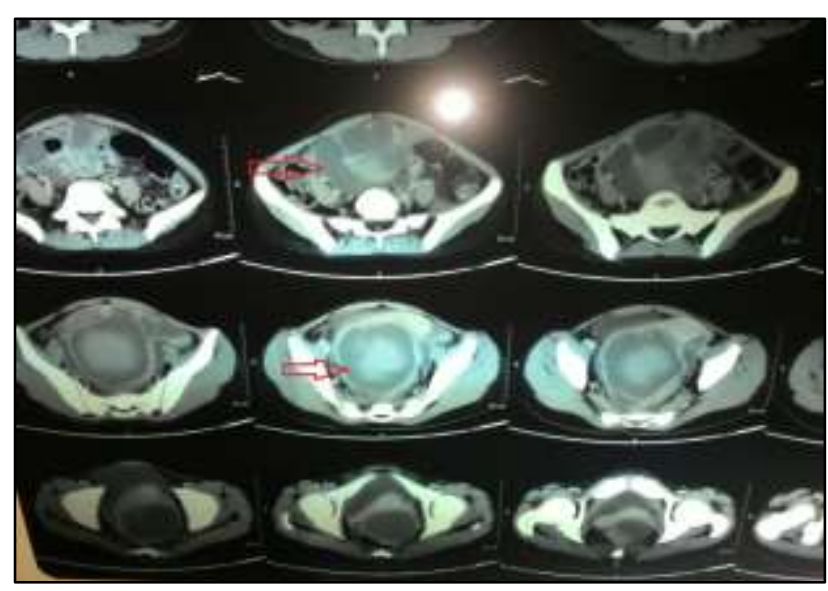

Figure 1: CT scan report of the patient showing the large pelvic lesion. Red arrow shows the large multicystic mass in the right adnexa.

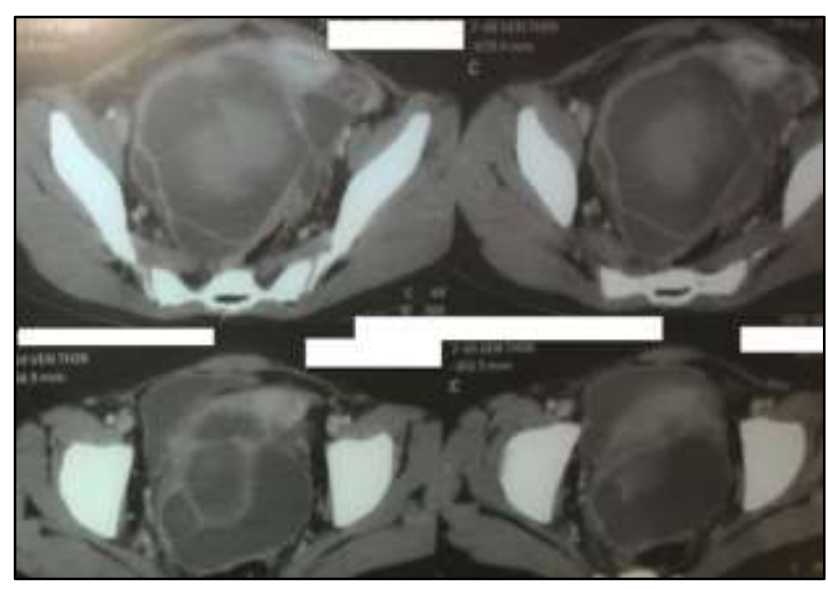

Figure 2: $10.8 \times 14 \times 16 \mathrm{~cm}$ multicystic mass from right adnexa extending to the entire pelvis along with areas of hemorrhage within it.

The recurrent features seen in GT are purpura, epistaxis, gingival bleeding and menorrhagia in females. Laboratory evaluation exhibits prolonged bleeding time with normal platelet count and morphology and a normal coagulation profile. Typical features seen in platelet aggregation studies include impaired clot retraction time with impaired platelet aggregation with ADP, 
epinephrine and collagen due to the dependence of these factors on fibrinogen attachment to the platelet for aggregation. Platelet aggregation occurs normally in response to ristocetin due to its independence from fibrinogen. ${ }^{6}$ Receptor assay using flow cytometry can be done to detect the presence of the GPIIb-IIIa complex, GPIIb (CD41), GPIIIa, (CD61) and fibrinogen by using monoclonal antibodies .The same method is used to detect the carrier status of family members with this disorder. ${ }^{7}$ The management of patients with GT is challenging and requires multidisciplinary approach. The severity of bleeding varies from mild to serious life threatening hemorrhage requiring aggressive therapy. Medical treatment includes antifibrinolytic agents (tranexamic acid), initial high dose of progestins followed by combined oestrogen and progesterone pills cyclically for maintenance. Blood and blood products are administered to correct anemia. Every transfusion increases the risk of alloimmunization; hence increasing the susceptibility to a massive hemorrhage. ${ }^{8}$ All patients need to be vaccinated against Hepatitis $B$ and medications affecting platelet function should be avoided. Repeated platelet transfusions lead to platelet refractoriness by formation of platelet glycoprotein antibodies and Human Leucocyte Antigen (HLA) immunization. Such cases benefit from newer modalities of treatment such as Factor VIIa therapy. This drug was developed for treatment of patients with hemophilia, but was later successfully used to treat hemorrhage from bleeding disorders such as GT. ${ }^{9}$ Menorrhagia in Glanzmann's thrombasthenia has also been successfully treated with Factor VII therapy. ${ }^{10}$ Plasmapheresis is the treatment of choice in patients who have already developed alloimmunization. Endometriosis is another reported complication seen in these patients. ${ }^{11}$ Pregnancy and delivery is very high risk in these patients as blood, blood products transfusion along with Factor VIIa therapy is required.

\section{CONCLUSION}

Prognosis of patients with Glanzmann's Thrombasthenia is good when necessary supportive care is provided. Spontaneous bleeding is uncommon but post traumatic bleed can be serious. This case highlights the need to consider medical measures before surgical intervention in women with such rare coagulation disorders.
Funding: No funding sources Conflict of interest: None declared Ethical approval: Not required

\section{REFERENCES}

1. Pittman MA Jr, Graham JB. Glanzmann's thrombopathy: an autosomal recessive trait in one family. Am J Med Sci. 1964;247:293-303.

2. Glanzmann E. Hereditaire Hamorrhagische thrombasthenic. Ein Beitrag Zur Pathologie der Blutplattchen. Jahrbuch Kinderheilkde. 1918;88:142.

3. Poon MC. Clinical use of recombinant human activated factor VII (rFVIIa) in the prevention and treatment of bleeding episodes in patients with Glanzmann's thrombasthenia. Vasc Health Risk Manag. 2007;3:655-64.

4. George JN, Caen JP, Nurden AT. Glanzmann's thrombasthenia: the spectrum of clinical disease. Blood. 1990;75:1383-95.

5. Bisch FC, Bowen KJ, Hanson BS, Kudryk VL, Billman MA. Dental considerations for a Glanzmann's thrombasthenia patient: case report. J Periodontol. 1996;67:536-40.

6. Fernandes Gomes M, de Melo RM, Plens G, Pontes EM, Silva MM, Da Rocha JC. Surgical and clinical management of a patient with Glanzmann's thrombasthenia: a case report. Quintessence Int. 2004;35:617-20.

7. Sharp WJ, Khanduri UD, Christie BS. Rapid heterozygote detection in Glanzmann's thrombasthenia.Br J Haematol. 1998;101:66-9.

8. Kantarci A, Cebeci I, Firatli E, Atamer T, Tuncer O. Periodontal management of Glanzmann's thrombasthenia: report of 3 cases. J Periodontol. 1996;67:816-20.

9. Franchini M, Zaffanello M, Veneri D. Recombinant factor VIIa. An update on its clinical use. Thromb Haemost. 2005;93:1027-35.

10. Yasemin I, Aysun K, Sibel K, Ismail S, Ali K. Intensive menstrual bleeding successfully treated with recombinant factor VIIa in Glanzmann's thrombasthenia. Clin Appl Thrombo Hemost. 2011;17:320-2.

11. Alatas E, Oztekin O, Hacioglu SK. Endometriosis in two sisters with Glanzmann's thrombasthenia. Fertil Steril. 2009;92:1496-8.

Cite this article as: Satia MN, Jandhyala M, More $\mathrm{V}$, Shanmukhaiah C. Conservative management of a complex ovarian cyst in a case of Glanzmann's thrombasthenia. Int J Reprod Contracept Obstet Gynecol 2016;5:2052-4. 